\title{
A PROPOSED MODEL ON SECU DRONE FOR SURVEILLANCE AND SECURITY CHECK
}

\author{
Satheesh Kumar P \\ Assistant Professor \\ Department of ECE \\ Coimbatore Institute of Technology, \\ Coimbatore, India
}

\author{
Karthik Jaikumar RP, Kaushik R, Maha Vishnu P, Jeeva Ananth C, Mohamed Nawfal A \\ UG Student \\ Department of ECE, \\ Coimbatore Institute of Technology, \\ Coimbatore, India
}

\begin{abstract}
Besides the commercial and surveillance applications of drones increasing enormously, there is no doubt in the efficacy. This article is on surveillance check and implementation of security system for ATM robbery. The recent incidences, challenging the security and safety measures currently used at ATM machines. In this paper, whenever robbery occurs, vibration sensor synchronised with GSM module and PIC controller alerts the management system, as well as closes the door and sprays Anaesthesia to make the thief unconscious using stepper motor synchronised with PIC controller. The application of drone is to track the thief, even he/she escapes from the encounter. Camera continuously process and sends the video to the PC and it will be saved in computer. In this proposal, the main idea is to save the money from robber(s) besides capturing them using a sensor system and drone.
\end{abstract}

Keywords: GSM module, Electronic speed controllers, Drone, autonomous aerial Vehicle.

\section{INTRODUCTION}

The progression in communication, networking and sensing technologies has involved researchers, hobbyists, and investors to deploy mini-drones, a.k.a. unmanned air vehicles (UAVs). Nowadays, autonomous systems are gaining good popularity. As the digitization systems has been increased and the installation of Debit and credit card is demanded. Thereby, banking activity has been simplified. However, the crime rate in proportion to the ratio of spreading out of automation machines in the financial organization has been increased at faster rate. Those crimes for the financial organization have been increased gradually from year 1999 to 2015, little bit decreased in 2004, and then increased again from year 2005. In the year of 2007, 212,530 of theft and 4,439 of robber cases are occurred, and 269,410 of theft and 4,409 of robber cases are chanced in year 2010 and in the year 2011, 270,109 of theft and 4,509 of robber cases are transpired. The Minister of State (MoS) well found this information for Finance in the Lok Sabha in response to a question regarding the number of ATM thefts, and the safety of financial outposts in the country. Among the crime cases related to financial organization, the cases of theft and robbery have high proportion of over $90 \%$ and the crime rate against ATM has been increased, because the usage of external ATM has been increased and it is always exposed to the crime. The banking sector lost a total of Rs 168.74 crore to organised crime focused at ATMs in the past three years. This includes figures for the first quarter of FY19. Between April and June 2018, 261 incidents were reported, entailing a loss of Rs 18.85 crore to banks. In the first quarter of the present financial year, 261 attempts at robbery have already been recorded, with the loss pegged at Rs 18.85 crore $^{[1]}$.

Therefore, this article is on suggesting the method of rapid reaction and minimization of loss by detecting the ATM machine. Using the GSM technology, Vibration sensor, DC Motor, Stepper Motor, unconscious gas theft of external ATM machine can be predicted. In this project we are using buzzer to give signal for corresponding bank and police station. Camera is used to take the continuous video clips $^{[3]}$. The current verification scheme in ATM is the usage of PIN (Personal Identification Number) numbers as key. In spite of growing number of thefts and the surge in trial, banks made few strongminded efforts to implement uniform security measures at their ATM amenities.

\section{NEED OF THE INNOVATION}

The use of drones for achieving high-speed wireless communication is one of the most important applications for next-generation communication systems. The FBI and its law enforcement followers round the country pursue hundreds of bank burglars whose uniqueness are unidentifiable. The project comes with detect the ATM theft from robberies and salvage the money. In 2016, the FBI hurled its Bank Robbers mobile app to make it even easier for the public to help recognize bank robbers ${ }^{[12]}$. 


\section{International Journal of Engineering Applied Sciences and Technology, 2020 Vol. 5, Issue 2, ISSN No. 2455-2143, Pages 423-427 \\ Published Online June 2020 in IJEAST (http://www.ijeast.com)}

\section{LITERATURE SURVEY}

Venka reddy maram, et. Al.(2018), in their work addressed about ATM theft prevention using GSM module and MEM sensor. When thief tries to break the ATM, movement is observed by MEM sensor and it activates the GSM module. The GSM unit sends the vigilant message to control room. About the merit of this proposal is that it sends vigilant message to the controller room and it also provides additional security to the ATM.On the other hand, it does not contain GPS module to know the location of thief, such that we cannot capture or track the thief.

Anurag singh rajpoot,et.al., (2016) in their work explains about the maximum weight exciting capability of the Quadcopter and other parameters to support drone such as transmitter-receiver, electronic speed controllers (ESCs), PID control, gyroscope, etc. The paper emphasizes Quadcopter cost- effective, reliable and stable in windy and dusty environment. Drone is highly stabilized and the weight lifting capacity of the drone can be estimated. But at the same time, the major issue is that is to adjust or tune the parameters of PID to obtain the set point.

Victor Massague Respall, et.,al, (2018) in their work enlightened the implementation of autonomous aerial vehicle (UAV) to detect, track and land in the vicinity of a moving Unmanned Ground Vehicle (UGV). The quadcopter needs to identify and track the target using camera-based perception. It tracks the thief automatically using camerabased perception. But, when colour-based detection algorithm is used, we cannot track the vehicles in night time.

\section{PROPOSED MODEL}

This proposal treats with the stoppage of ATM robbery and to overcome the drawback found in existing technology. Whenever theft occurs, the thief tries to snatch the cash from ATM. The PIR sensor senses the dispatchment of cash box. Surpassing that, the accelerometric sensor senses the abnormal change in the position of the ATM cash box. Similarly, Force sensor senses the abnormal force applied onto the ATM box. All these signals activate the door lock. Door is locked by using stepper motor. Sensor systems enables GSM module to send emergency alert to control room. On receiving the alert, anaesthesia at an advisable concentration is sprayed inside the room. In case still the thief manages to escape, drone tracks thief by sending GPS - controlled signal to control room. This system uses PIC controller to route real time data collected using the sensors. Camera sends processing videos continuously to the PC and saves in the computer. GSM module sends the alert message at the time of robbery to the control station and to the respective bank through the GSM. This will stops the robbery and the person involving in robbery can be caught easily. Drone is used to track the thief if he manages to escape by breaking the door. Proteus software is used to run the stepper motor for automatic door lock and also to leakage the gas inside the ATM room. Thus, the solution for the problem statement makes the ATM robberies decreased and reduces the number of crimes happening for financial organizations.

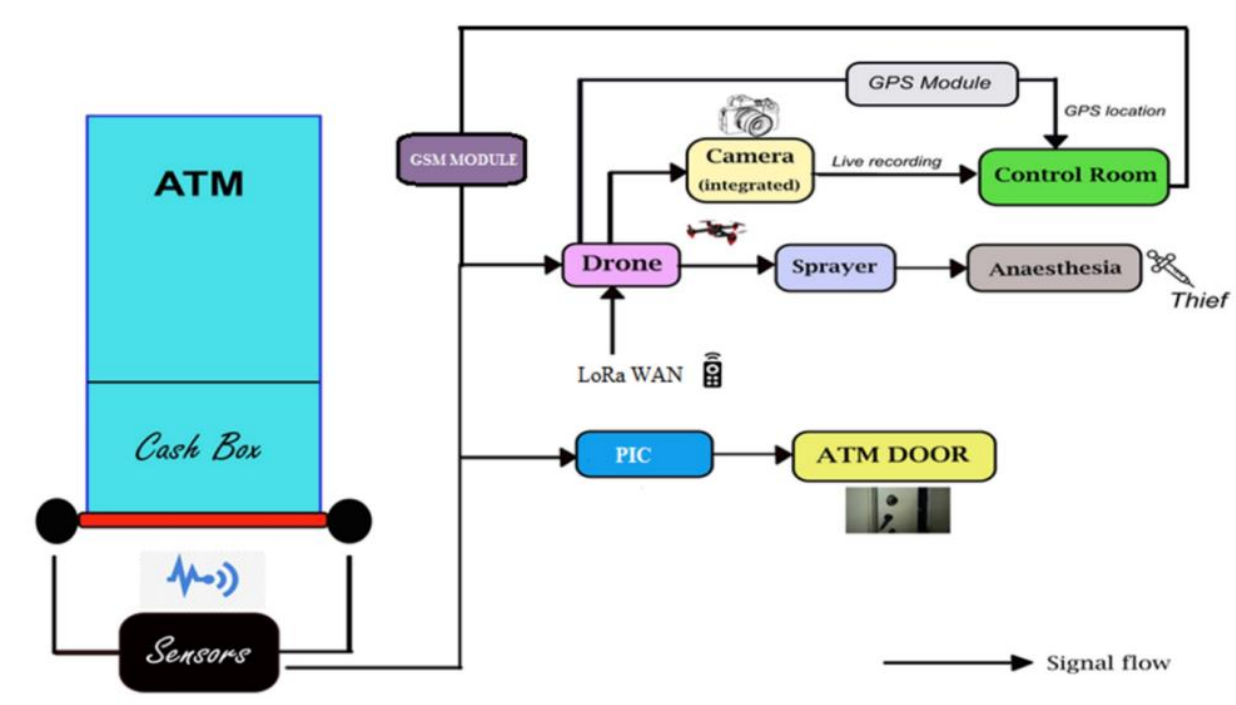

Fig.1 BLOCK DIAGRAM OF PROPOSED MODEL

\section{DESCRIPTION}

The sensor system used in this idea consists of three sensors namely - PIR, Accelerometric, Force sensor. A PIR sensor is an electronic sensor measures Infrared (IR) light blistering from objects in its field of view. Here, the role of the sensor is to monitor the unauthorized entry of the thief into the ATM room. The PIR sensor in the sensor system has the Sensitivity range is up to 6 meters with $110^{\circ} \times 70^{\circ}$ detection range. So, normally when a thief enters and to snatch up the cash from cash box, the PIR sensor can sense the motion of the thief and produces specified output. 


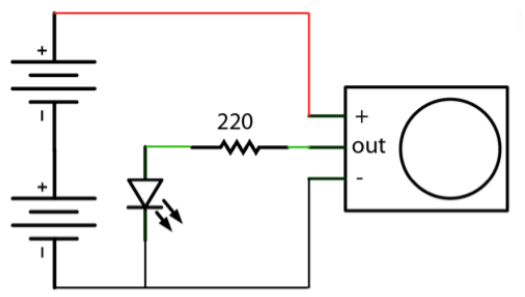

FIG.2 INTERNAL BLOCK DIAGRAM OF PIR SENSOR

The next one to be discussed is the accelerometric sensor. The accelerometric sensor is to detect the change in the physical three-dimensional position of the cash box of the ATM. These sensors may have full range up to $+/-3 g$. Meanwhile, this sensor is also compact, does not requires more than $3.6 \mathrm{~V}$ for operation. Here, when the thief tries to snatch up the cash box, the accelerometric sensor senses the change in the position of the cash box.

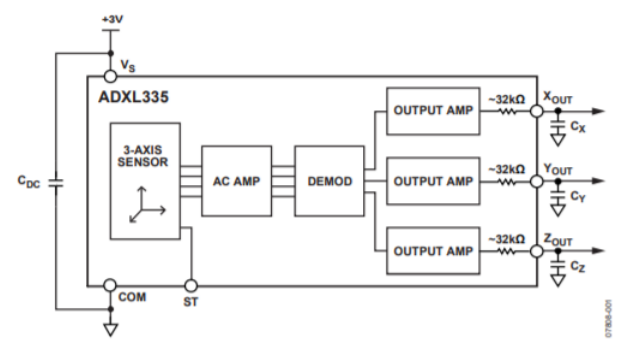

FIG.3 INTERNAL BLOCK DIAGRAM OF ACCELEROMETRIC SENSOR

Finally, the force sensor is used to ensure that thief due to some abnormal force applied on it is disturbing the cash box. This sensor can sense the force normally in the range of $1 \mathrm{~N}-15 \mathrm{~N}$. Whenever the thief applies abnormal force over the cash box, the actuation of the sensor helps to acknowledge the entry of thief.

These sensors are integrated with the door lock of the ATM and the sprayer to foam a advisable amount of anaesthesia to make the thief faint inside the ATM for a while. This idea is to capture the thief within the ATM room. The role of the drone is to track or monitor the thief despite he escapes from these layers of security. The drone keeps on sending the location of the thief by tracking him throughout the way thief travels

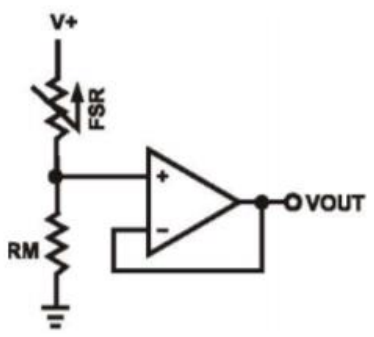

\section{FIG.4 INTERNAL BLOCK DIAGRAM OF FORCE SENSOR WIRELESS CAMERA}

The wireless monitoring video camera and wireless receiver set for surveillance. By installing the wireless camera in the ATM room, where to monitor and set the wireless receiver in the nearby room (up to 0 to 15 meters away from the ATM room) to store the footage for the security records for necessary action. Depiction of AV Receiver of wireless camera sends video footages to the Computer.

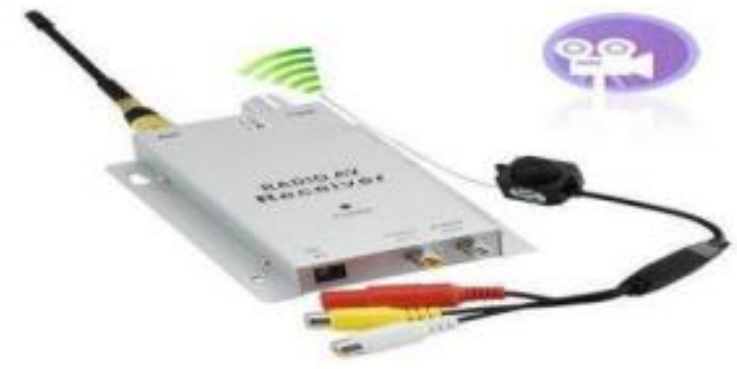

Fig. 5 AV RECEIVER AND WIRELESS CAMERA.

\section{STEPPER MOTOR AND DC MOTORS}

Stepper motors and DC motors that move in discrete steps. The multiple coils organized in groups are called phases. By employing each phase in sequential order, the motor will rotate by one step at a time. With a computer controlled stepper motor, it can precise positioning or in order and also controls the speed. In this system, stepper motor is used for anaesthesia gas leakage inside the room of the ATM to unconscious the thief.

\section{SIMULATION OUTPUT}

SOFTWARE USED: NI Multisim 14.0 
International Journal of Engineering Applied Sciences and Technology, 2020

Vol. 5, Issue 2, ISSN No. 2455-2143, Pages 423-427

Published Online June 2020 in IJEAST (http://www.ijeast.com)

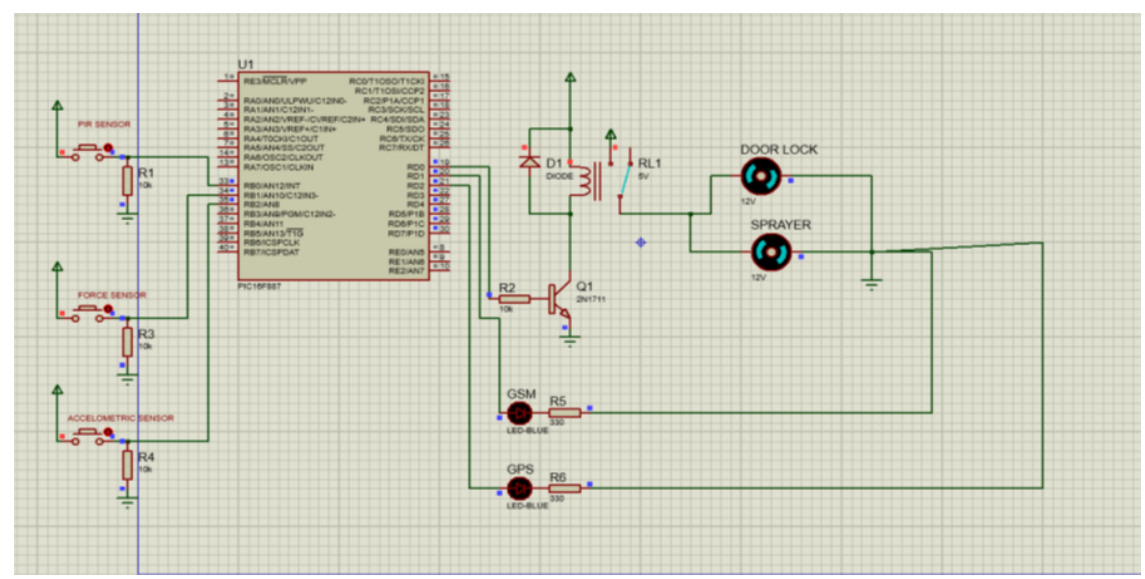

FIG.5 STATE OF THE PROPOSED SECURITY SYSTEM WHEN THERE IS NO DETECTION OF THIEF

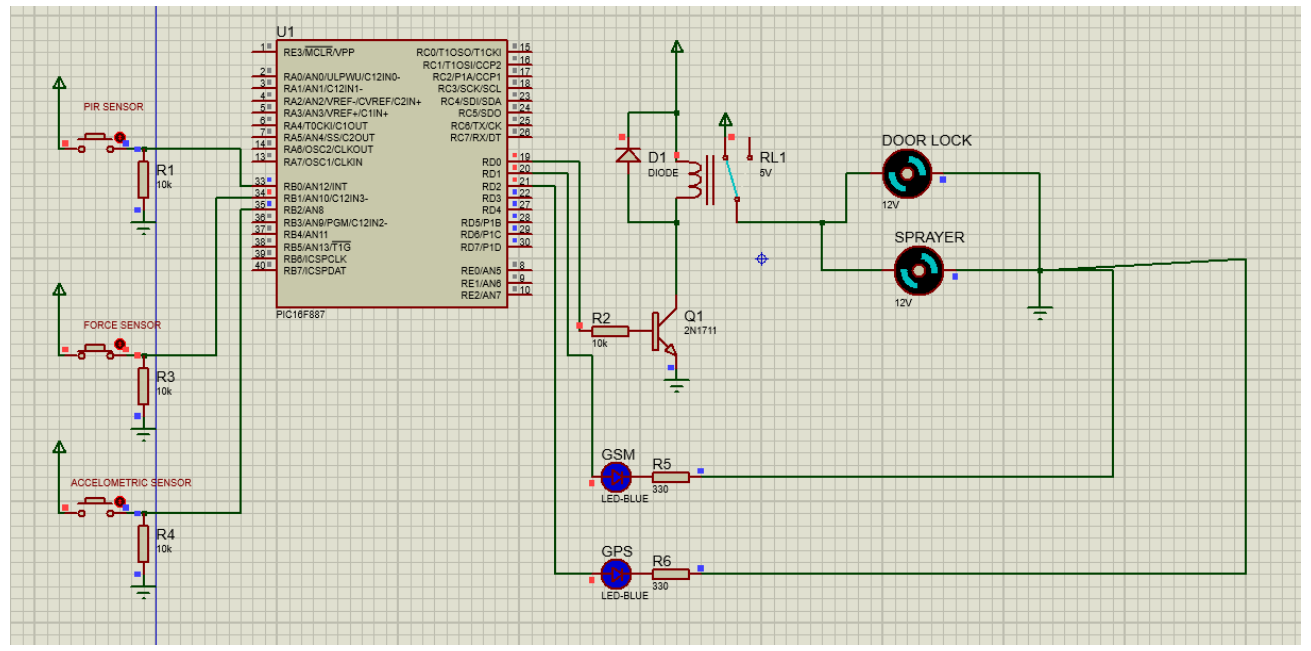

FIG.6 STATE OF THE PROPOSED SECURITY SYSTEM WHEN THERE'S A DETECTION OF THIEF

\section{CONCLUSION}

By considering the above parameters, the ATM preventionusing drone is useful for the upcoming future society. By keeping this project as a prototype, more innovations can be discovered. Image processing methods can be done for entire time period (day and night). As per this project, it can give a great result, which is more efficient than the previous proposal. As a result of this proposal, it helps to prevent the theft and ensures immediate action against the thieves and minimizes the time of cops in capturing the thieves. The system ensures 24/7 protection to all the ATMs. New technology like LORA can also be used along with this for the future advancement.

\section{ACKNOWLEDGEMENT}

Our heartful thanks to the management of Coimbatore Institute of Technology, Coimbatore for providing us with the necessary infrastructure towards completion of our project. We take immense pleasure to express our heartfelt thanks to our principal Dr. V. Selladurai, Ph.D., for providing us with the necessary facilities that enabled us to successfully complete our project. We sincerely thank the efforts taken by Dr. A. Rajeswari, Ph.D., Professor and Head, Department of Electronics and Communication Engineering, Coimbatore Institute of Technology for her valuable ideas in completing our project efficiently.

\section{REFERENCES}

[1]. Vishal Sharma ; Dushantha Nalin K. Jayakody ; Ilsun You ; Ravinder Kumar ; Jun Li (2018), "Secure and Efficient Context-Aware Localization of Drones in Urban Scenarios", IEEE Communications Magazine ( Volume: 56 , Issue: 4, DOI: 10.1109/MCOM.2018.1700434

[2]. Johann-Sebastian Pleban, Ricardo Band, Reiner Creutzburg(2014), "Hacking and securing the AR.Drone 2.0 quadcopter: investigations for improving the security of a toy", Proceedings Volume 9030, Mobile Devices and Multimedia: Enabling 
Technologies, Algorithms, and Application;90300L https://doi.org/10.1117/12.2044868

[3]. Guruprasad, Nagarathna, Nandini, Roja, Vijayakumar, (2017) "Smart ATM Supervision System using GSM", International Journal of Research and Scientific Innovation, Vol.4, Issue 6, ISSN 23212705

[4]. Sunyoung Cho, Dae Hoe Kim, Young Woon Park, (2017) "Learning Drone-control Actions in Surveillance Videos", $17^{\text {th }}$ International Journal of Automation and systems, Vol.6, Issue.09.

[5]. Tony Holt and Jon Spencer,(2005), "A Little Yellow Box: The Targeting of Automatic Teller Machines as a Strategy in Reducing Street Robbery", Crime Prevention and Community Safety : An International Journal, 10.1057/palgrave.cpcs.8140215

[6]. Paul Ekblom (2014), "Design and Security", The Handbook of Security, Palgrave Macmillan, a division of Nature America Inc.,

[7]. Bernardo Bátiz-Lazo and Claudia Reese(2010), "Is the future of the ATM past?", Financial Markets and Organizational Technologies, Palgrave Macmillan, a division of Macmillan Publishers Limited, 2010.
[8]. J. D. Rae (2014), "National Security and the Efficacy of Drone Warfare", ( ) James DeShaw Rae.

[9]. Rob T. Guerette and Ronald V. Clarke, (2013), "Product Life Cycles and Crime: Automated Teller Machines and Robbery", Security Journal.

[10]. Venka reddy maram , Mirza sajid ali baig,(2018) "Advanced Security Management System for ATM's using GSM and MEMS", IEEE 2321-8665 Vol.03,Issue.03.

[11]. Anurag singh rajpoot, Namrata gadani , Sagar kalathia,(2017) "Development of Arduino Based Quadcopter ", IEEE Vol. 3, Issue 6,

[12]. Victor Massague Respall, Sami Sellami, Ilya Afanasyev, (2018) "Implementation of Autonomous Visual Detection, Tracking and Landing for Quadcopter", IEEE Vol. 5, Issue 5.

[13]. https://www.fbi.gov/investigate/violent-crime/bankrobbery.

[14]. Jongho Won, Seunghyun Seo profile imageSeungHyun Seo,E. Bertino profile imageElisa Bertino (2015), "A Secure Communication Protocol for drones and Smart Objects", doi$10.1145 / 2714576.2714616$ 